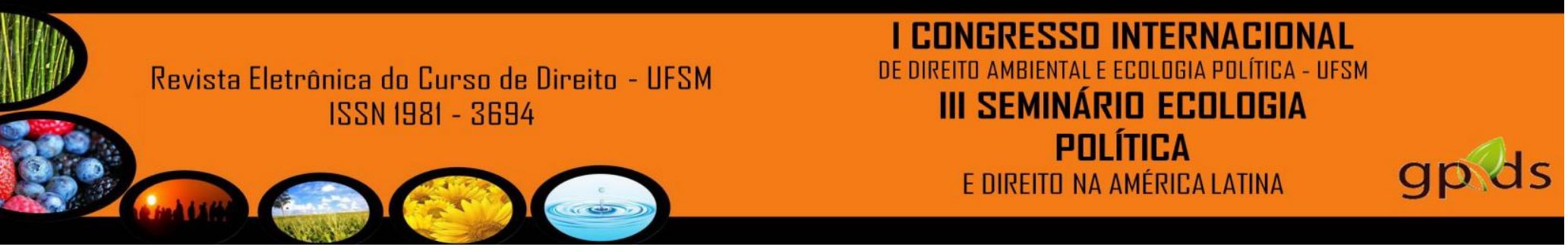

\title{
UMA ANÁLISE DA SOCIEDADE DE RISCO SOB O ASPECTO DA PROTEÇÃO DAS ÁGUAS SUBTERRÂNEAS
}

\author{
Natacha John ${ }^{1}$ \\ Fernanda Favarini Odorissi ${ }^{2}$ \\ Rene Keller ${ }^{3}$
}

\section{Resumo}

Este trabalho apresenta como tema central o estudo da proteção das águas subterrâneas frente à sociedade de risco. Assim, tem-se como objetivo demonstrar como o processo de modernização contribuiu para o surgimento da chamada sociedade de risco e os perigos que ela apresenta na contaminação das águas subterrâneas. Desse modo, utilizando o método indutivo de pesquisa pela natureza do estudo desenvolvido, por se adequar aos objetivos propostos e valendo-se da pesquisa bibliográfica como fonte para a formação argumentativa, constatou-se ser necessária a mudança nos padrões de comportamento adotados atualmente, tendo em vista a gama de interesses e conflitos que estão envolvidos na questão da contaminação das águas subterrâneas e também para prevenção dos riscos que oferecem para sociedade.

Palavras-chave: Sociedade de risco. Águas subterrâneas. Legislação ambiental.

\section{INTRODUÇÃO}

A humanidade se desenvolve em um ritmo muito acelerado, onde a visão estritamente econômica a respeito do crescimento de nossa sociedade faz com que os riscos decorrentes deste desenvolvimento sejam, muitas vezes, esquecidos.

Desde uma operação individual, até as ações em massa, todos os acontecimentos presentes na sociedade pós-moderna acarretam em conseqüências globais e, junto a elas, a possibilidade de danos não previstos. São ameaças que incidirão, principalmente, no

\footnotetext{
${ }^{1}$ Mestranda em Direito (UCS), área de concentração em Direito Ambiental e Sociedade, na linha de pesquisa Direito Ambiental e Novos Direitos. Graduada pelo Centro Universitário Franciscano UNIFRA. Advogada. Integrante do grupo de pesquisa Alfabetização Ecológica, Cultura e Jurisdição: uma incursão pelas teorias da decisão (UCS). Email: natachajohn@ hotmail.com

2 Advogada, mestranda em Direito pela Universidade de Caxias do Sul - UCS, especialista em Direito Público pela Escola da Magistratura Federal - ESMAFE. Graduada em Direito pela Faculdade de Direito de Santa Maria - FADISMA.

${ }^{3}$ Mestrando em Direito na Universidade de Caxias do Sul (UCS) e bolsista CAPES, área de concentração em Direito Ambiental e Sociedade. Graduado em Direito pela Pontifícia Universidade Católica do Rio Grande do Sul (PUCRS). Email: rene.j.keller@gmail.com
} 

principalmente, no meio ambiente que nos cerca e, por consequência, contra a própria existência do homem na Terra.

Ulrich Beck, ao fazer uma abordagem percussora do conceito de sociedade de risco (Risikogesellschaft), acaba delineando uma comparação necessariamente existente entre a crise ecológica e o atual processo de globalização, as descobertas tecnológicas, o sujeito cada vez mais particularizado e as políticas econômicas capitalistas que permeiam nosso meio.

Ainda neste sentindo, BECK (2004, p. 36) ainda explica que os riscos não se esgotam em efeitos e danos já ocorridos. Neles, exprime-se um componente futuro e este se baseia em parte na extensão futura dos danos atualmente previsíveis e em parte numa perda geral de confiança ou num suposto "amplificador do risco". Riscos tem que ver com antecipação, com destruições que não ocorreram ainda, todavia, que são iminentes, e que já são reais hoje. Os riscos mostram um futuro que necessita ser evitado. Os riscos ainda mostram-se simultaneamente reais e irreais. Assim, de um lado, muitas ameaças e destruições já são reais, como rios poluídos, destruição florestal, entre outros. De outro lado, a verdadeira força social do argumento do risco mora nas ameaças projetadas no futuro. Desse modo, o núcleo da consciência do risco não reside no presente, mas sim no futuro. Na sociedade de risco, portanto, o passado deixa de ter força determinante em relação ao presente. _

$\mathrm{O}$ autor supra, vai mais longe ao mencionar que devemos nos tornar ativos hoje para evitar e atenuar, problemas ou crises do amanhã ou do depois do amanhã, para tomar precauções em relação a eles. Refere que no debate com o futuro nós temos que lidar com uma "variável projetada", uma "causa projetada" da atuação (pessoal e política) presente, cuja importância e significado crescem em proporção direta à sua incalculabilidade e ao seu teor de ameaça e que concebemos para definir e organizar a nossa atuação presente. (2004, p. 40)

Segundo BECK (2004), isto pressupõe que os riscos sejam bemsucedidos num processo de reconhecimento social. Riscos são inicialmente bens de rejeição. Assim, as situações de ameaça precisam romper o privilégio da tabuização que as cerca e "nascer cientificamente". Isto ocorre sob a forma de um "efeito colateral latente" que admite e legitima a realidade da ameaça, ou seja, equivale a uma espécie de 
III SEMINÁRII ECOLOGIA

POLÍTICA

licença, a um destino natural civilizatório, que ao mesmo tempo reconhece, distribui seletivamente e justifica efeitos a serem evitados.

$\mathrm{Na}$ verdade, trata-se de um momento histórico posterior à modernidade industrial, agora denominada sociedade reflexiva, onde não mais se podem prever as ameaças concomitantes ao desenvolvimento do homem.(BECK, 1998, p. 201) De tal modo que a utilização dos recursos naturais excede a capacidade de regeneração ou substituição por outras fontes alternativas. Além disso, a forma como vem ocorrendo o desenvolvimento tecnológico acaba provocando grandes problemas ambientais, pois a grande produção e o consumo exagerado causam um crescente esgotamento das fontes naturais. Neste seguimento, importante salientar conforme expressou JONAS(2006, p.67):

a promessa da tecnologia moderna se converteu em ameaça, ou esta se associou àquela de forma indissolúvel.[...] Concebida para a felicidade humana, a submissão da natureza, na sobremedida de seu sucesso,que agora se estende à própria natureza do homem, conduziu ao maior desafio já posto ao ser humano pela sua própria ação.

Assim, acabamos por originar os denominados passivos ambientais, sendo a poluição das águas subterrâneas, um dos resultados do modelo produtivo deste desenvolvimento adotado pela sociedade, colocando em risco a saúde de toda coletividade.

Conforme refere GIDDENS (1991, p. 25) estamos vivendo um momento de desorientação que a sociedade não consegue conviver com certas situações e acaba ocorrendo uma falta de controle. De acordo com BECK (1998, p. 210), estamos vivendo uma rescisão da sociedade industrial clássica, com o declínio de suas instituições, presenciando o surgimento de uma sociedade complexa, marcada predominantemente pelos riscos, incertezas e constantes transformações, dominando os sentimentos de dúvida e insegurança quanto aos próximos passos da humanidade.

Diante das considerações referidas, emerge questionamentos acerca do modelo de desenvolvimento adotado, pois apesar dos grandes avanços tecnológicos, existe o adensamento dos problemas sócio-ambientais em uma grande dimensão, expondo a sociedade a riscos e perigos constantes.Neste panorama de falta de apreço dos limites naturais do planeta em prol ao crescimento econômico, insere-se a importância da 
Em verdade, da abundância de água doce disponível na Terra, uma parcela muito pequena se encontra na forma de rios e lagos, sendo que o restante é na forma de águas subterrâneas. Estima-se que o percentual de água disponível na superfície é de $1,2 \%$ e o restante, cerca de $98 \%$ apresenta-se na forma subterrânea. GRAF (2003, p. 62) anota que em muitos países as águas subterrâneas representam a única forma de abastecimento, como é caso da Arábia Saudita, Dinamarca e Malta. Em países como Bélgica, França, Hungria, Itália, Suíça entre outros cerca de $70 \%$ do abastecimento ocorre através das águas subterrâneas.

Ao que refere à utilização das águas subterrâneas, observa-se ser claramente mais proveitoso para o homem uma vez que é de melhor qualidade e obtida com um valor inferior ao da água tratada. $\mathrm{O}$ aumento da poluição e o imperativo de implementação de saneamento básico, fazem com que os custos para tornar a água adequada para o consumo, sejam cada vez mais elevados. Assim, muitas pessoas têm investido em perfuração de poços artesianos domésticos.

No entanto, segundo SILVA, (2003. p. 710)este cenário causa apreensão, haja vista que existe o risco de contaminação dos aquíferos, pois o resultado da utilização em grande proporção é desconhecido, sendo que não existe um controle ativo da contaminação das águas superficiais. Deste modo, percebemos que devemos agir com cautela, aplicando o princípio da precaução, consoante o qual "as pessoas e o seu meio ambiente devem ter em seu favor o benefício da dúvida quando haja incerteza sobre se uma dada ação os vai prejudicar"

Leciona FREITAS (2001, p. 56) que se por um lado as águas subterrâneas estão mais protegidas da poluição que os corpos d'água superficiais, por outro lado depois de poluídas, demoram milhares de anos para retornarem ao normal. Já no que se refere aos rios e lagos em 15 ou 20 dias, se renovam.Visível, no caso em tela que se deve cada vez mais investir em prevenção e proteção dos aquíferos, sendo imprescindível uma política mundial da água, que vise o gerenciamento em conjunto de referido recurso ambiental.

Neste sentido expõe Viegas ao dizer que:

"Na esfera prática, uma das medidas a serem tomadas em relação à problemática da água é adoção de uma política mundial da água, que importe em um gerenciamento apropriado desse recurso ambiental. Tal medida vem sendo realçada pela comunidade ligada ao assunto em diversos eventos. Com efeito, a Terra constitui-se em uma grande porção de área separada 
III SEMINÁRID ECDLDGIA

PDLÍTICA

E DIREITO NA AMÉRICA LATINA

politicamente em territórios independentes, mas interligados quando se trata de questões envolvendo a degradação ambiental, que repercute sem respeitar fronteiras. Assim, ocorre, por exemplo, quando um rio transpõe mais de um Estado, a tal ponto que a poluição gerada mais próximo à sua nascente alcançará a foz, que não raro se situa em país diverso daquele que causou a degradação ambienta"(VIEGAS 2003, p. 59)

Além do mais, preconiza SILVA (2003, p. 153): "A proteção das águas subterrâneas é uma questão estratégica. No Brasil, mais da metade de água de abastecimento público provém de reservas subterrâneas" que o entendimento majoritário no que diz respeito a águas subterrâneas é de servir como fonte reserva, ou melhor, de recurso "alternativo", que somente seria usada quando a água superficial não estivesse mais acessível para consumo ou ainda nas regiões que desprovidas de água acima do solo.

Importante consideração acerca das águas subterrâneas assevera no seguinte fato REBOUÇAS (1997, p. 88):

"Ela é fonte fundamental de suprimento da umidade do solo que dá suporte ao desenvolvimento da cobertura vegetal-natural ou cultivada. Além disso, ela é fonte primordial de regularização dos fluxos dos rios durante os períodos de estiagem, e de abastecimento em geral, à medida que é extraída de forma adequada por meio de poços, fontes ou nascentes e outras formas de captação."

Por fim, também precisamos atentar para questão das águas subterrâneas, uma vez que contamos com o mais vasto reservatório de água doce do mundo. O Aqüífero Guarani, que se estende, além do Brasil, pelo Uruguai, Paraguai e Argentina.

\section{A proteção das águas subterrâneas na sociedade de risco e a legislação ambiental}

\section{brasileira}

Inúmeras são as causas que levaram a sociedade ao estágio atual de crise, entretanto o homem não conseguiu tirar os ensinamentos suficientes, continuando a atuar de forma irresponsável em relação à utilização dos recursos hídricos superficiais, bem como na questão dos recursos hídricos subterrâneos. A gestão das águas subterrâneas enfrenta o desafio de resguardar um bem oculto, envolvendo dois recursos da natureza: água e solo, sendo que a dificuldade aumenta, uma vez que as águas 
subterrâneas dependem da ciência para revelar os perigos e ameaças, tais que não podem ser observados pelos leigos.

Os riscos de dano ambiental podem ter diversas origens, podendo se asseverar um caráter multidimensional, entretanto acaba causando uma dificuldade na previsibilidade do risco. Na questão em tela, mais precisamente somente conseguimos perceber o dano através de procedimentos técnicos. A relação de dependência com a ciência para conseguir constatar se houve ou não algum tipo de dano, é umas das principais dificuldades apresentadas, uma vez que o controle das águas subterrâneas é pequeno e sua dinâmica ainda é muito pouco conhecida.

Outro fator BECK (1998, p. 68) relevante que merece ser destacado é a falta de conhecimento e informação por parte da sociedade, o que acaba excluindo a população sobre qualquer dinâmica em que se trata de águas subterrâneas.Cada sociedade mantém "uma relação com riscos", uma forma característica de enfrentá-los, que transparece em um plano cultural. Essa relação de riscos muda conforme as épocas e os lugares.

O direito não poderia ficar impassível a questão dos problemas ambientais, sendo um dos principais instrumentos para constituir a vida em sociedade e para tutela das condições fundamentais e o seu livre desenvolvimento. FERREIRA (2004, p. 119) analisa que as leis ambientais existentes, não conseguem controlar os riscos da sociedade atual e consequentemente as que surgem posteriormente, espelham-se e perpetuam, por querer ou involuntariamente em um sistema que já arruinado, propondo uma falsa normalidade.

Atualmente vive-se uma conjuntura social que não se consegue mais dimensionar os riscos ao qual estamos expostos, tanto na economia, política e sociedade, pois cada vez mais se encontram fora do alcance das instituições estabelecidas para o controle e supervisão. Nossa Constituição Federal, por sua vez, concebeu o caráter de direito e dever fundamental de todos à preservação de um meio ecologicamente equilibrado, importante referir SILVA:

“O que é importante - escrevemos de outra feita - é que se tenha a consciência de que o direito à vida, como matriz de todos os demais direitos fundamentais do Homem, é que há de orientar todas as formas de atuação no campo da tutela do meio ambiente. Cumpre compreender que ele é um fator preponderante, que há de estar acima de quaisquer outras considerações como as de desenvolvimento, como as de respeito ao direito de propriedade, 
como as da iniciativa privada. Também estes são garantidos no texto constitucional, mas, a toda evidência, não podem primar sobre o direito fundamental à vida, que está em jogo quando se discute a tutela da qualidade do meio ambiente. É que a tutela da qualidade do meio ambiente é instrumental no sentido de que, através dela, o que se protege é um valor maior: a qualidade de vida." (SILVA, 2003. p. 70)

Assim, impõe tanto ao Poder Público como à coletividade o dever de preserválo e defendê-lo para as presentes e futuras gerações. Observa-se ainda ser o nosso sistema jurídico ambiental constituído por vasta legislação protetiva do ambiente, incluindo as águas.

No entanto, a explícita degradação que o homem vem causando à natureza e sua inércia sobre a real existência de uma sociedade de risco demonstra que as normas ambientais vigentes, embora modernas, carecem de real eficácia, tanto jurídica quanto social. Em uma época em que as indetermináveis consequências da evolução tecnológica e do desenvolvimento representam concretas ameaças à sociedade, tal constatação toma graus assustadores e preocupantes, pois conforme PRIGOGINE (1996, p. 14):“assistimos ao surgimento de uma ciência que não mais se limita a situações simplificadas, idealizadas, mas nos põe diante da complexidade do mundo real"

Mesmo assim, a legislação possui grande importância como mecanismo de acesso ao recurso, como também o consumo e a repartição dos benefícios e custos. Entretanto, vale ressaltar que de nada adianta uma edição desenfreada de leis especificamente no caso em tela sobre águas subterrâneas, se sua eficácia ainda é muito remota e distante.

Diante do cenário atual, o que se percebe é que a legislação sobre águas subterrâneas seja ela federal estadual ou municipal se tornou muito pouco operacional, cabendo à sociedade exigir o seu cumprimento, através dos mecanismos legais existentes. No entanto, para que tais medidas sejam adotadas pela sociedade é necessário à implementação de políticas públicas para garantir a sustentabilidade dos aquíferos para estas e futuras gerações, assim como prescreve o artigo 225 da Carta Maior. Ainda neste sentido, importante ressaltar a contribuição da Lei no 9.433/97, que 
III SEMINÁRII ECDLOGIA

POLÍTICA

estabeleceu literalmente que "a água é um recurso natural limitado". Ainda assim GRAFF (2003, p. 52-53):

\footnotetext{
“em 08.01.1997 foi editada a Lei 9.433, que institui uma política nacional especifica para os recursos hídricos, adotando novos paradigmas quanto aos usos múltiplos das águas, à participação popular na gestão destes recursos e, reconhecendo que se trata de um recurso finito, vulnerável e, dotado de valor econômico"
}

Ao desenvolver políticas públicas neste contexto, ocorreria o reconhecimento da limitação ecológica dos recursos naturais, bem como empecilho da exploração ruinosa até sua finitude, como bem assevera SILVA (1997, p. 75):“Nossa legislação estava moldada a uma visão inesgotabilidade dos recursos hídricos e tinha como preocupação primordial o uso da água com finalidades de produção de energia”.

Contudo, apenas um plano de política pública isolado não obteria sucesso, para tanto é necessário ações conjuntas e articuladas com outras políticas de desenvolvimento atinente a economia, ao social, aos transportes, à habitação, ao saneamento básico, à saúde entre outras.

Analisando o panorama atual se percebe que independentemente da forma como vai ocorrer à participação da população nas questões atinentes aos recursos hídricos, ela é fundamental. A questão da água era em regra geral resolvida pela administração pública, que apenas tinha a preocupação em satisfazer as necessidades com um recurso natural abundante e gratuito distribuído para todos de forma igualitária e com a mesma qualidade.

Contudo, a situação atual se alterou, estamos diante de um recurso finito, escasso em muitos locais e em se tratando de águas subterrâneas ainda existe os conflitos relacionados à ocupação do solo. Desse modo, a participação social é muito importante como forma de exercer a fiscalização e a cobrança do Poder Público. Entretanto, para que esta fiscalização e pressão ocorram de forma adequada, de modo a preservar o meio ambiente e principalmente as águas subterrâneas é necessário que a população tenha conhecimento da necessidade de proteger esse recurso, assim como as medidas necessárias para tal conscientização. 
Importante salientar que devem ser feitos esclarecimentos básicos, mas de caráter essencial, como explicar o que é um aquífero, o que são áreas de superexploração e contaminação, sendo fundamental para que a população possa atuar na defesa do patrimônio ambiental. Ao contrário, o risco da população acabar manipulada e optar por defender interesses aparentemente atrativos em curto prazo ignorando os efeitos futuros são grandes. Por fim, de forma ilustrativa podemos citar novamente o Aquífero Guarani, que embora de forma modesta, já ocorre a participação popular, no processo de medidas efetivas de proteção. Contudo, representa ainda os primeiros passos da participação da população no gerenciamento dos riscos.

\section{CONSIDERAÇÕES FINAIS}

A sociedade de risco é caracterizada pela produção industrial de riqueza e consequentemente pela produção social do risco. O avanço técnico e científico tão enaltecido por muitos, somente apresenta suas consequências negativas em longo prazo e infelizmente não são percebidos pela realidade atual.

$\mathrm{Na}$ modernidade o desenvolvimento não ocorre de forma simultânea com os recursos naturais, ou seja, o crescimento frenético da sociedade não acompanha o processo de regeneração ou substituição dos recursos naturais. Em que pese à questão da água na sociedade de risco, percebe-se que sua utilização não pode mais ocorrer de forma irracional, uma vez que já foi constatado a finitude deste recurso natural.A água é a fonte da vida. Assim, importante mencionar que ter acesso à água potável em quantidade satisfatória não é uma questão de opção, mas de obrigação básica, apresentando-se como direito fundamental e elemento essencial para a dignidade humana.

Refere o autor PETRELLA (2002, p. 24) que "podemos sobreviver sem internet, sem petróleo, sem fundo de investimentos ou uma conta bancária. Mas - um argumento banal, embora frequentemente esquecido - não nos é possível viver sem água", elucidando ainda que o petróleo pode ser substituído por carvão.Vale ressaltar que as águas subterrâneas não podem ser utilizadas de maneira irresponsável, devido sua estrita relação com as águas superficiais, tendo como consequiência a poluição dos aquíferos. Esse problema de ordem ambiental tem desafiado o Poder Público e até 


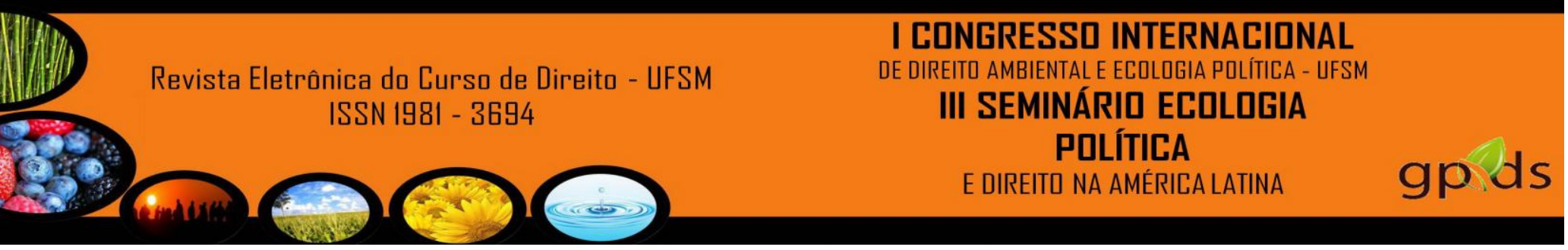

mesmo a sociedade na procura de soluções para utilização dos recursos naturais, de modo a não gerar tantos riscos a coletividade.

A poluição das águas subterrâneas, assim como muitos outros problemas de degradação ambiental, implica em riscos para própria humanidade e ao ambiente em todas as suas formas de vida, nos fazendo repensar sobre o modelo de sociedade ao qual fazemos parte.É necessário iniciarmos uma mudança, seja na economia, na política ou na sociedade, entretanto esta mudança deve iniciar principalmente no comportamento individual de cada cidadão e papel que desempenha dentro da coletividade. As transformações são urgentes e bem vindas para resgatar o bem de valor mais valioso que possuímos: a vida.

\section{REFERÊNCIAS BIBLIOGÁFICAS}

BECK, Ulrich. La sociedad del risgo. Hacia uma nueva modernidad. Barcelona: Paidós, 1998.

Sociedade de Risco: rumo a uma outra modernidade. Tradução de Sebastião Nascimento. São Paulo: Editora 34, 2004.

GIDDENS, Anthony. LASH, Scott. Modernização Reflexiva. São Paulo: Editora Unesp, 1997.

BARLOW Maude; CLARKE,Tony. Ouro Azul. São Paulo: M. Books, 2003.

CAPOBIANCO, João Paulo Ribeiro. Fonte de água pura. Resenha do livro Águas doce do Brasil: capital ecológico, uso e conservação. Editora Escrituras, coordenação de Aldo Rebouças, Benedoto Braga e José Glizia Tundisi. Parabólicas, n. 55, Nov/dez/99. Disponível em: <http://socioambiental.org/parabolicas/index.html>. Acesso em: 12 de março de 2012.

FERREIRA, Heleni Sivini. A globalização, a sociedade de risco, a dimensão preventiva do direito e ambiente. In: Estado de Direito Ambiental: Tendência: Aspectos Constitucionais e Diagnósticos; Heleni Sivini Ferreira, José Rubens Morato Leite (Orgs). Rio de Janeiro: Forense Universitária, 2004.

FREITAS, Fabiana Paschoal de. Águas Subterrâneas Transfronteiriças: o aquíffero Guarani e o projeto do GEF/Banco Mundial. In: Congresso Internacional de Direito Ambiental. 7., 2003. Direito, Água e Vida. São Paulo: Imprensa Oficial, 2003. 


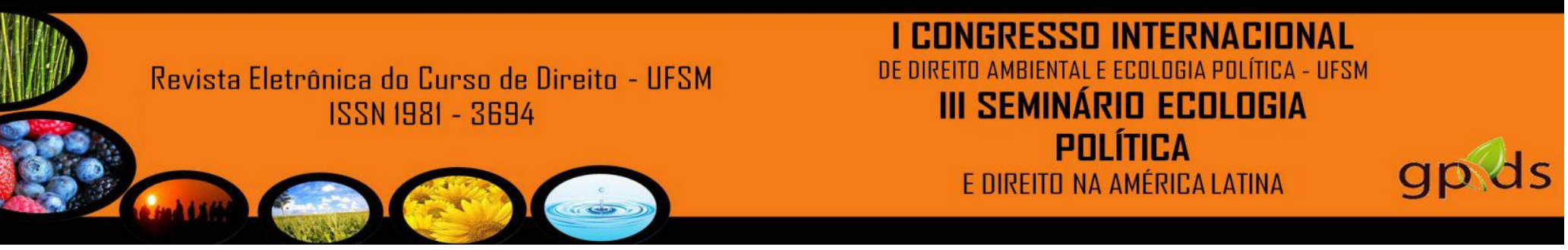

FREITAS, Vladimir Passos de. Sistema Jurídico brasileiro de controle da poluição das águas subterrâneas. Revista de Direito Ambiental, São Paulo, a.6, n. 23, p. 53-66. jul./set. 2001.

GIDDENS, Anthony. As conseqüências da Modernidade. Editora UNESP, 1991.

GRAF, Ana Cláudia Bento. A Tutela dos Estados sobre as Águas. In: FREITAS, Vladimir Passos de (Org.). Águas: aspectos jurídicos e ambientais. 2. ed. Curitiba: Juruá, 2003.

JONAS, Hans. O princípio responsabilidade: ensaio de uma ética para a civilização tecnológica. Tradução de Marijane Lisboa, Luiz Barros Montez. Rio de Janeiro: Contraponto; Ed. da PUC-Rio, 2006.

PETRELLA, Riccardo. O Manifesto da Água: argumentos para um contrato mundial. Tradução Vera Lúcia Mello Joscelyne. Petrópolis, Rio de Janeiro: Vozes, 2002.

POMPEU, Cid Tomanik. Controle da Poluição Hídrica no Brasil. Revista de Direito Administrativo, Rio de Janeiro, n. 130, p. 425-439, ou./dez. 1977.

PRIGOGINE, Ilya. O fim das certezas. Tempo, caos e as leis da natureza. Tradução de Roberto Leal Ferreira. São Paulo: Unesp, 1996.

REBOUÇAS, Aldo da C. Panorama da Água Doce no Brasil. In: Panoramas da degradação do ar, da água doce e da terra no Brasil. São Paulo: IEA/USP, 1997.

SILVA, Fernando Quadros da. A Gestão dos Recursos Hídricos após a Lei 9.433, de 08 de janeiro de 1997. In: Freitas, Vladimir Passos de (Org). Direito Ambiental em Evolução. Curitiba: Juruá, 1998.

SILVA, José Alfonso da. Direito Ambiental Constitucional. 4. ed. São Paulo: Malheiros, 2003.

SILVA, Luís Praxades Vieira da. Principio da Precaução e Recursos Hídricos. In: Congresso Internacional de Direito Ambiental. 7, 2003. Direito, Água e Vida. São Paulo: Imprensa Oficial, 2003.

SILVA, Solange Teles da. Aspectos Jurídicos das Águas Subterrâneas. Revista de Direito Ambiental. São Paulo, a. 8, n. 32, p. 159, dez. 2003. 


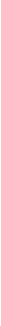

VIEGAS, Eduardo Coral. Gestão da água e princípios ambientais. Caxias do Sul, RS:

Educs, 2008. 